\title{
Familial aortic dissection: a report of rare family cluster
}

\author{
MASAAKI TOYAMA, ATSUSHI AMANO, TAKAAKI KAMEDA \\ From the Department of Cardiovascular Surgery, Kameda General Hospital, Chiba, Japan
}

SUMMARY Acute aortic dissection occurred in three of four siblings without Marfan syndrome. All of them were successfully treated by operation and remain well 6-42 months after operation. Their mother died suddenly in another hospital of acute aortic dissection. All her siblings were dead and cardiovascular disease was suspected in all of them.

Aortic dissection is a relatively common catastrophic disease, but it is unusual to find the disease in four close relatives-three siblings and their mother.

\section{Patients and methods}

\section{CASE 1}

This 31 year old Japanese man (the second son) who was $170 \mathrm{~cm}$ tall and weighed $66 \mathrm{~kg}$ was brought into the emergency room with severe pain in the back and right leg on 8 January 1984. He had no previous history of these symptoms. Cyanosis was evident and there was no right radial pulse. Arterial pressure (146/72 $\mathrm{mm} \mathrm{Hg}$ on arrival) quickly fell to $60 / 30$ $\mathrm{mm} \mathrm{Hg}$. There was an audible regurgitant murmur (3/6) of the aortic valve. Cross sectional echocardiography showed a flapping movement in the ascending aorta. The aortic annulus was $3.0 \mathrm{~cm}$ in diameter. There was no evidence of mitral valve abnormality. An emergency operation was performed. An intimal tear was identified at $3 \mathrm{~cm}$ above the sinotubular junction and three quarters of the aortic circumference was dissected. The aortic valve commissures were suspended with pledgetted sutures and the transected aorta was reinforced with Tefion felt and anastomosed together. Several hours after the patient was transferred to the intensive care unit urine flow ceased and serum potassium began to rise. Emergency haemodialysis was started and was maintained every other day for three weeks until renal function returned to normal. After postoperative rehabilitation the patient was discharged four months after operation. In the outpatient clinic after discharge a physical examination was performed to

Requests for reprints to Dr Masaaki Toyama, Department of Cardiovascular Surgery, Kameda General Hospital, 929 Higashicho Kamogawa City, Chiba, 296 Japan.

Accepted for publication 22 September 1988 rule out Marfan syndrome. The ratio of the upper segment to the lower segment was $1 \cdot 3$, the arm span $\phi$ was $162 \mathrm{~cm}$, and the metacarpal index was 7 . Thumb? sign and wrist sign were negative and the lens were normal. The greatest anterior-posterior measurement of the thorax was $23 \mathrm{~cm}$ and of normal ${ }_{\infty}$ shape.

CASE 2

The elder brother of case 1 , who was 34 years old, $167 \mathrm{~cm}$ tall and weighed $67 \mathrm{~kg}$, walked into theô emergency room on 18 May 1984 with mild chest $\stackrel{\mathscr{Q}}{\circ}$

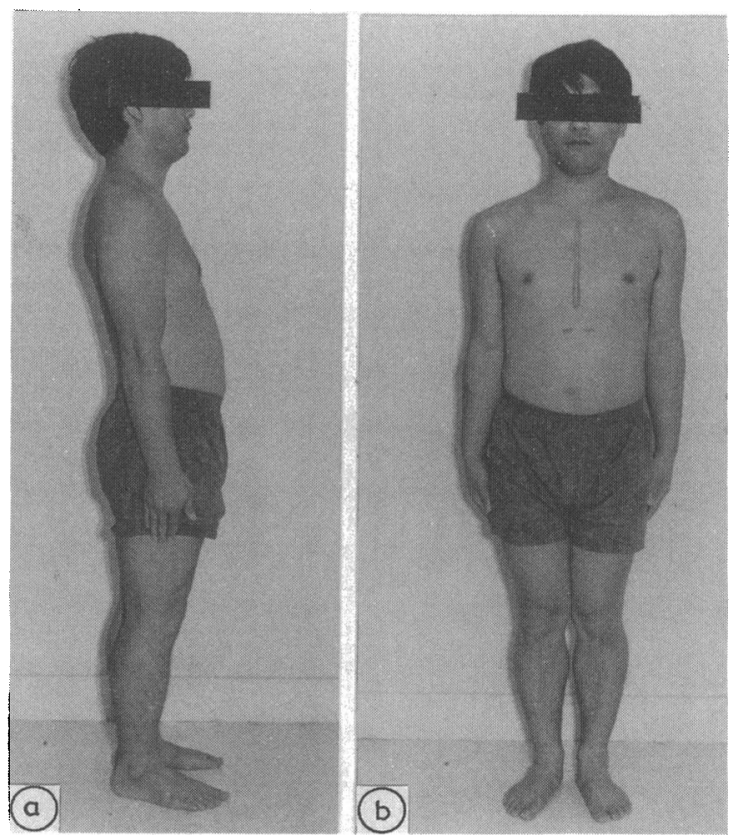

Fig 1 Photograph of case 2. 


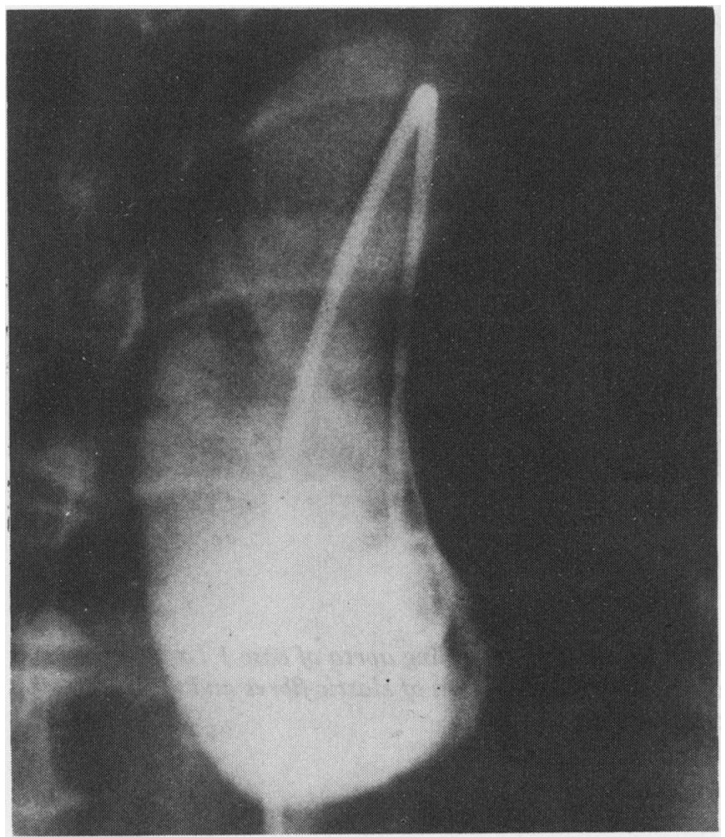

Fig 2 Aortogram of aortic root in case 3 showing the typical shape of annuloaortic ectasia.

pain and headache that had developed that morning. An aortic regurgitant murmur was audible. Echocardiography and computed tomography showed a DeBakey type I dissection. The aortic annulus was $3.2 \mathrm{~cm}$ in diameter and mitral valve prolapse was not evident. Examination of the eyes showed no evidence of abnormality except for moderate myopia. The skeletal system was apparently normal. The arm span was $156 \mathrm{~cm}$, the upper segment to lower segment ratio was 1.33 , the metacarpal index was 6.6 , and the thumb sign and wrist sign were negative. Chest $x$ rays and studies of pulmonary function were normal. Because haemodynamic function remained stable and chest pain was controlled with medication, operation was performed three weeks later on a semielective basis. The ascending aorta was dilated to an aneurysmal degree and there was an intimal tear $2 \mathrm{~cm}$ distal to the sinotubular junction. The aortic valve commissures were resuspended and a huge aneurysm was replaced with woven graft. Apart from the development of postoperative psychosis the postoperative course was uneventful. He was discharged 50 days after operation. Figure 1 shows a photograph of this patient.

\section{CASE 3}

The 39 year old sister of cases 1 and 2 was brought to the emergency room by ambulance on 14 January 1987 with a one day history of lumbago and epigastric

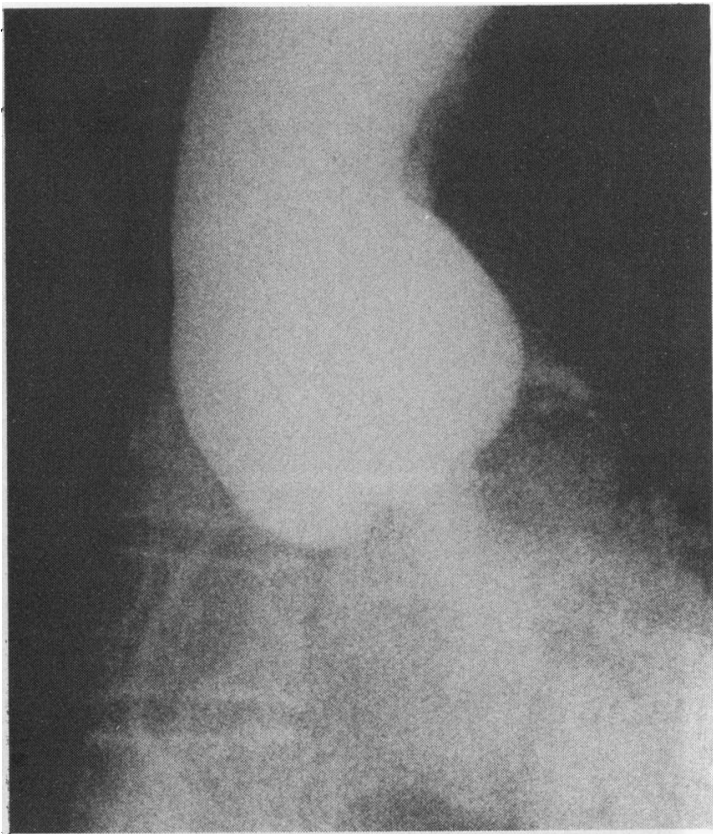

Fig 3 Aortogram of aortic root of case 4 also showing the typical shape of annuloaortic ectasia with appreciable aortic regurgitation.

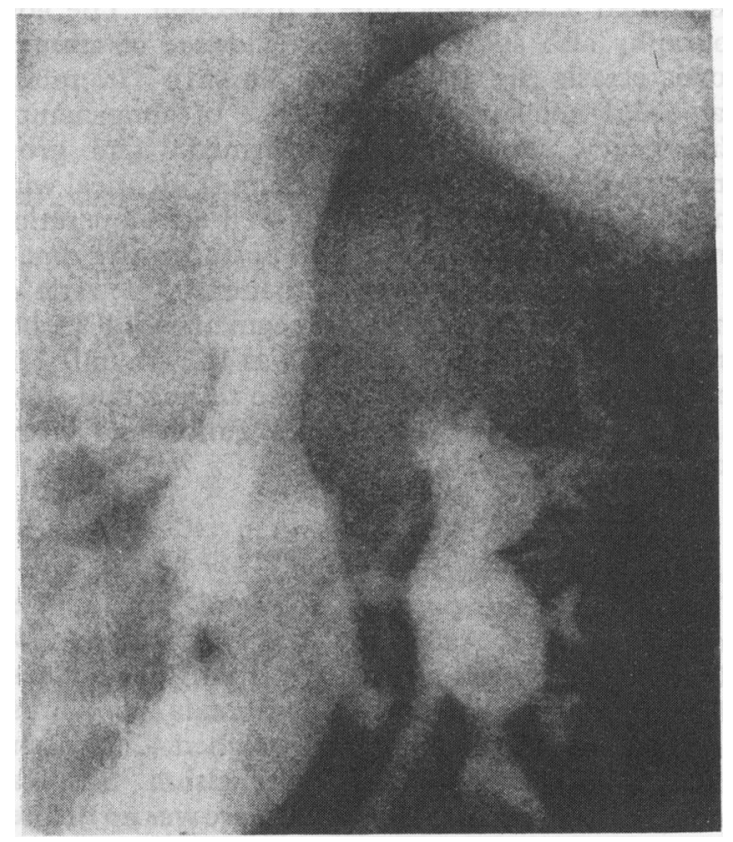

Fig 4 Abdominal aortography in case 4 showing a dissected intimal flap. 


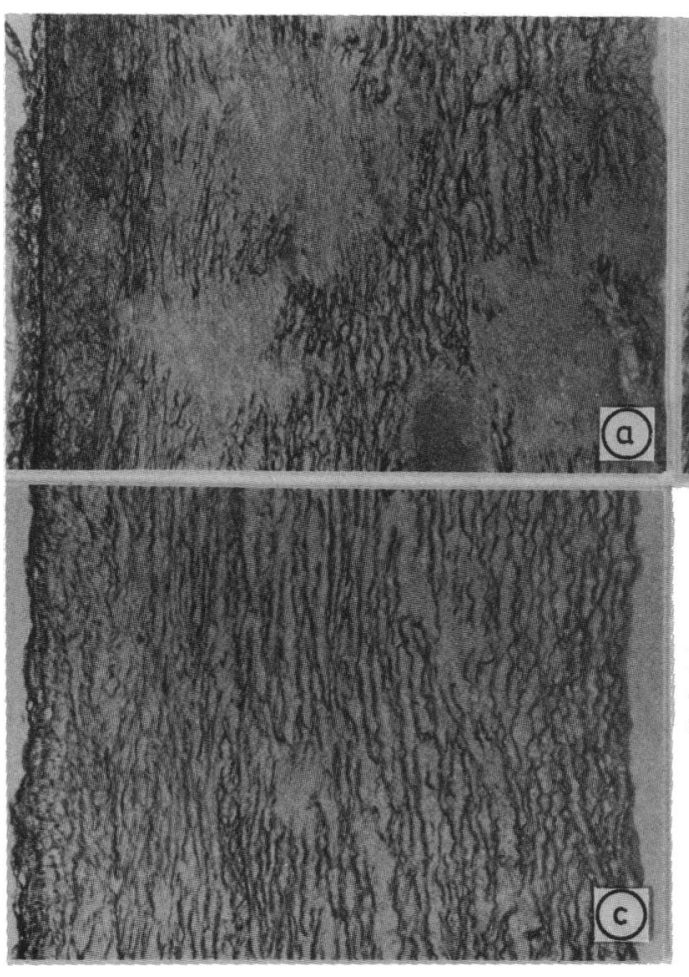

pain. Because of her family history, aortic dissection was suspected. Echocardiography and aortography confirmed a DeBakey type I dissection. The aortography also showed typical evidence of annuloaortic ectasia (fig 2) (diameter $3.6 \mathrm{~cm}$ ). The mitral valve did not show any evidence of abnormality. Emergency surgery was performed. The gross anatomy of dissected aorta was almost identical with those of her brothers. She did well after operation and was discharged on the $23 \mathrm{rd}$ postoperative day.

She was examined as an outpatient. The ratio of the upper segment to the lower segment was 1.31 , her arm span was $130 \mathrm{~cm}$, and she was $142 \mathrm{~cm}$ tall. The metacarpal index was 6.8 and the thumb and wrist signs were negative. Her lenses, fundi, and visual acuity were normal.

\section{CASE 4}

The mother of our patients died aged 55 in another hospital in 1978. According to the information we obtained, she was admitted complaining of shortness of breath on exertion and with anorexia. On admission, she was $153.4 \mathrm{~cm}$ tall and weighed $42.2 \mathrm{~kg}$; she did not have a history of hypertension. She was known to have normal vision but there was no further information on her eyes. Cardiac catheterisation showed annuloaortic ectasia with grade 2 aortic regurgitation (fig 3) and type III aortic dissection (fig⿳亠丷⿵冂丶 4). The diameter of the ascending aorta was $5.6 \mathrm{~cm}^{\circ}$ and that of the aortic annulus was $3.9 \mathrm{~cm}$. Gastroin $-\overrightarrow{\overrightarrow{0}}$ testinal investigation disclosed advanced stomach cancer. She died suddenly soon afterwards. The family refused permission for a necropsy.

\section{Discussion}

There are eleven previous reports of familial aortic. dissection. ${ }^{1-11}$ Nine of the 23 family members had features suggestive of Marfan syndrome but in 14 patients it was not clear if they had Marfan syn-o drome. Half of these cases were reported before medical and surgical treatment for acute aortico. dissection was available and 21 of the 23 patients died. Necropsy was performed in most patients and showed a tear in the ascending aorta in 15 patients and in the descending aorta in six..$^{3-10}$ Histologica $N^{-}$ examination was carried out in 17 patients and thereo was medial necrosis in 16 . Only one had a normat histology of aorta. ${ }^{11}$

Our three patients are most unusual because none? of the family had features of the Marfan syndrome oro a history of hypertension and all three survived and were rehabilitated after emergency operation. His $\frac{\mathbb{}}{8}$ tological examination of the aorta showed disruption of elastic fibres and medial necrosis in all three 


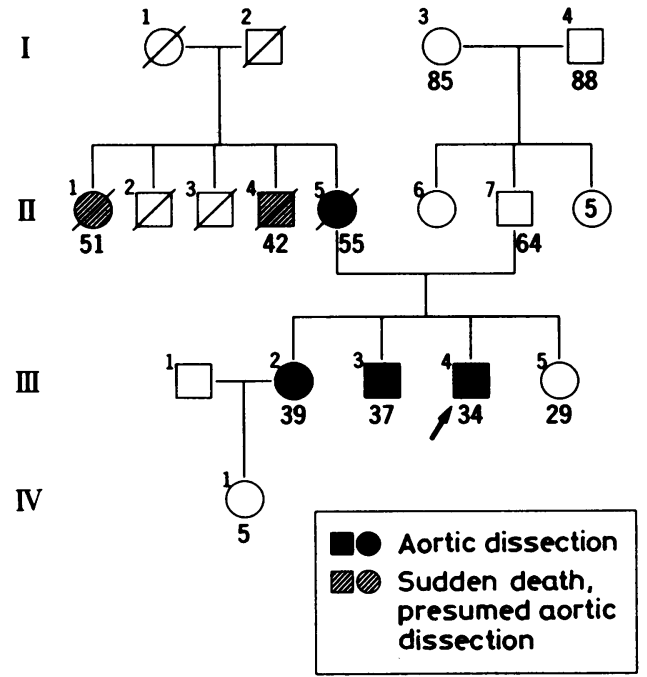

Fig 6 Family pedigree. Squares and circles are males and females respectively.

patients (fig 5). Nobody from the mother's family is alive and a cardiovascular cause of death was suspected in almost all of them. All members of the father's family are alive and well (fig 6). There was no intermarriage. The youngest sister is 29 and at present does not show any signs of aortic dissection. She will be examined by echocardiography every year to detect enlargement of the aortic annulus and aorta. If an aortic aneurysm is found it can be operated on to prevent dissection. There is a 50:50 risk of her being affected.
References

1 Griffiths GJ, Hayhurst AP, Whitehead R. Dissecting aneurysm of the aorta in mother and child. Br Heart $J$ 1951;13:364-8.

2 Graham JG, Milne JA. Dissecting aneurysm of the aorta: a review of 29 cases. Glas Med J 1952;33:320-9.

3 Whittaker SRF, Sheehan JD. Dissecting aortic aneurysm in Marfan's syndrome. Lancet 1954;ii: 791-2.

4 Massumi RA, Lowe EW, Misanik LF, Just H, Tawakkol A. Multiple aortic aneurysms (thoracic and abdominal) in twins with Marfan's syndrome: fatal rupture during pregnancy. $J$ Thorac Cardiovasc Surg 1967;53:223-30.

5 Hanley WB, Jones NB. Familial dissecting aortic aneurysm. A report of three cases within two generations. Br Heart J 1967;29:852-8.

6 Grondin CM, Steinberg CL, Edwards JE. Dissecting aneurysm complicating Marfan's syndrome (arachnodactyly) in a mother and son. Am Heart J 1969;77: 301-6.

7 Young D. Familial dissecting aneurysm complicating Marfan's syndrome. Am Heart J 1969;78:577-8.

8 Humphries JO, Ingle JN, Norum RA. Dissecting aneurysm of the aorta in mother and daughter. Birth Defects 1972;8:185-7.

9 Lichtenstein J. Erdheim's cystic medical necrosis in father and son. Birth Defects 1972;8:282-3.

10 Bixler D, Antley RM. Familial aortic dissection with iris anomalies-A new connective tissue disease syndrome? Birth Defects 1976:12:229-34.

11 Warnes CA, Kirkman PM, Roberts WC. Aortic dissection in more than one family member. Am J Cardiol 1985;55:236-8. 